\title{
Desenvolvimento de etapas educativas: o cemitério como condutor de uma aprendizagem significativa para o ensino de História
}

\author{
Desarrolo de etapas educativas: el cementerio como conductor de un \\ aprendizaje significante para la enseñanza de História
Development of educational stages: the cemetery as a conductor of a significant learning for the teaching of History

Maria Cristina Pastore ${ }^{1}$

\begin{abstract}
Resumo
Este trabalho visa apresentar as considerações teóricas metodológicas sobre a aula de história realizada no cemitério como experiência educativa. A experiência ocorreu em uma turma no primeiro ano do ensino médio, pretende demonstrar que as etapas foram desenvolvidas para despertar o interesse do aluno e contemplam pré e pós a aula-visita ao cemitério, momentos na sala de aula, tarefas realizadas no domicilio do estudante, assim como no próprio local da experiência. No transcorrer das ações educativas realizadas no espaço cemitério a partir de um conteúdo curricular desenvolvido em sala de aula na disciplina de História, a presente pesquisa procura refletir as peculiaridades do e para Ensino de História a partir do espaço inusitado e pouco explorado. Inverter a lógica de uma aula convencional parte do principio dialógico e da construção do conhecimento para uma aprendizagem significativa, propicia pensar a aula e suas especificidades, principalmente busca conectar os conteúdos com a vida do aluno através do lugar escolhido. O cemitério se apresenta como lugar de invisibilidade no urbano, local pouco explorado pelo ensino de história, no entanto, possui um potencial de provocar diversas reações. Esta proposta discute o método didático desenvolvido e apresenta o cemitério como agente aglutinador assim como a temática morte. A necessidade do aluno de se apropriar desses espaços como cultura, como patrimônio, como conhecimento e saberes cotidianos, se apresenta como resultado positivo da experiência educativa. Este recorte faz parte da tese de mestrado defendido em 2016 com o titulo: "Procedimento invertido: o ensino de história a partir das inquietações de jovens estudantes sobre morte na aula-visita ao cemitério".
\end{abstract}

Palavras chaves: Cemitério; Docente; Ensino; História; Morte;

\section{Resumen}

Este trabajo pretende presentar las consideraciones teóricas metodológicas sobre la clase de historia realizada en el cementerio como experiencia educativa. La experiencia ocurrió en una clase en el primer año de la enseñanza media, pretende demostrar que las etapas fueron desarrolladas para despertar el interés del alumno y contemplan pre y post la clase-visita al cementerio, momentos en el aula, tareas realizadas en el domicilio del estudiante, así como en el propio lugar de la experiencia. En el transcurso de las acciones educativas realizadas en el espacio cementerio a partir de un contenido curricular desarrollado en el aula en la disciplina de Historia, la presente investigación busca reflejar las peculiaridades del y para la enseñanza de la historia a partir del espacio inusitado y poco explorado. Invertir la lógica de una clase convencional parte del principio dialógico y de la construcción del conocimiento para un aprendizaje significativo, propicia pensar la clase y sus especificidades, principalmente busca conectar los contenidos con la vida del alumno a través del lugar escogido. El cementerio se presenta como lugar de invisibilidad en el urbano, local poco explorado por la enseñanza de la historia, sin embargo, posee un potencial de provocar diversas reacciones. Esta propuesta discute el método didáctico desarrollado y presenta el cementerio como agente aglutinador así como la temática muerte. La necesidad del alumno de apropiarse de esos espacios como cultura, como patrimonio, como conocimiento y saberes cotidianos, se presenta como resultado positivo de la experiencia educativa. Este recorte forma parte de la tesis de maestría

\footnotetext{
${ }^{1}$ Mestre em Ensino de História, FURG. Rio Grande, RS; Brasil; crisrgs2000@ yahoo.com.br
} 
defendida en 2016 con el título: "Procedimiento invertido: la enseñanza de historia a partir de las inquietudes de jóvenes estudiantes sobre muerte en la clase-visita al cementerio".

Palabras claves: Cementerio; enseñanza; la educación; la historia; la muerte;

\begin{abstract}
This work aims to present the theoretical methodological considerations about the history lesson held in the cemetery as an educational experience. The experiment took place in a class in the first year of high school and aims to demonstrate that the stages were developed to arouse the interest of the student and contemplate pre and post class - visit to the cemetery, moments in the classroom, tasks carried out at the student's home, as well as at the place of experience. In the course of the educational actions carried out in the cemetery space from a curricular content developed in the classroom of History, the present research seeks to reflect the peculiarities of and for Teaching History from the unusual space and little explored. Inverting the logic of a conventional class starts from the dialogical principle and the construction of knowledge for meaningful learning, allows to think about the classroom and its specificities, mainly to connect the contents with the life of the student through the chosen place. The cemetery presents itself as a place of invisibility in the urban, a place little explored by history teaching, however, it has the potential to provoke several reactions. This proposal discusses the didactic method developed and presents the graveyard as agglutination agent as well as the death theme. The student's need to appropriate these spaces as culture, as patrimony, as knowledge and everyday knowledge, presents itself as a positive result of the educational experience. This cut is part of the master thesis defended in 2016 with the title: "Reversed procedure: teaching history from the concerns of young students about death in class - visit to the cemetery."
\end{abstract}

Keywords: Cemetery; Teacher; Teaching; Story; Death

\title{
1. A estética do cemitério
}

A etimologia da palavra cemitério, de acordo com OTOBELLI \& VAILATTI, (2007, p 17) deriva do latim "coemiterium" que significa "lugar onde se dorme", que se origina do grego koimetérion, "quarto de dormir", se referindo aos termos que utilizamos como "ultima morada" ou "descanso eterno". Assim, a necrópole assume questionamentos históricos em uma perspectiva contemporânea e dentro de uma esfera realista da condição do ser humano, pois necessita de pensar a morte e o morrer. O morrer perpassa o tempo, a memória e a identidade dos atores nesse cenário. O cemitério está relacionado com esses elementos. O espaço cemitério, segundo Foucault conecta diversas culturas:

Exemplificarei com a estranha heterotopia que é o cemitério. Um cemitério é, em absoluto, um lugar diverso dos espaços culturais comuns. É, porém, um espaço intimamente relacionado com todos os outros sítios da cidade ou estado ou sociedade, etc., uma vez que cada indivíduo e cada família têm familiares no cemitério. Na cultura ocidental o cemitério sempre existiu, apesar de ter atravessado mudanças radicais. (FOUCAULT, 2001:417)

Descrever o cemitério como espaço que se posiciona fora do corpo urbano é tentar refletir a negação da morte, embora, hoje, o cemitério se constitui, fisicamente, parte da cidade. Sua visibilidade é comprometida. Na cidade do Rio Grande, localizado em uma área urbana valorizada, o cemitério é o lugar onde se dorme dentro do urbano. Onde se realiza uma prática antiga compartilhada: a reverência aos mortos. Percorrer suas ruas é perceber em seu 
silêncio, em meio ao caos urbano, sua dimensão social esquecida. Tendendo o deslocamento do real para o imaginário, no qual no campo da afetividade, do emocional, provoca comportamentos diversos e gera conflitos na atualidade.

O cemitério na configuração atual é uma construção imposta por lei. Sua formação deu-se por motivações de higiene e sanitárias, as quais eram providências necessárias para evitar as doenças que eram transmitidas pela decomposição dos corpos. Para TORRES (2015: 01) "Desde o século XVIII, os enterramentos eram feitos no interior das igrejas da cidade, mas a salubridade desta prática é amplamente questionada e legalmente proibida”. De acordo com o Professor Doutor da Universidade Federal do Rio Grande/RS Luiz Henrique Torres (2015), em Rio Grande a transmigração do cemitério antigo da Igreja do Bonfim (local de sepultamento para algumas personalidades da cidade) para o novo cemitério era um pedido da comunidade.

Porém, em outra localidade do Brasil, na Bahia, essa transferência não se deu de forma pacífica e ocorreu a Cemiterada, conforme nos conta João José Reis:

O episódio que ficou conhecido como Cemiterada, ocorreu em 25 de outubro de 1836. No dia seguinte entraria em vigor uma lei proibindo o tradicional costume de enterros nas igrejas e concedendo a uma companhia privada o monopólio dos enterros em Salvador por trinta anos. (REIS, 1991: 13)

Nesse processo, o cemitério, por um lado acolhedor por outro temido, encontra sua expressão estética. Conceitua-se estética a partir da dimensão da experiência e da ação do homem na visão de John Dewey (2010) pois toda criatura viva recebe e sofre influência do meio. O estético está relacionado com as experiências cotidianas e a forma como sentimos e interagimos com o meio. Nesse sentido, a estética do cemitério esta relacionada com a ação humana nesse lugar. Os sentidos, ou melhor, as representações sociais, políticas e culturais que traduzem a morte nesse meio, reduzem a capacidade de compreensão e aceitação do cemitério como lugar de aprendizagem.

Na composição dessa visão contemporânea, o cemitério busca identidade e aceitação, deixar de ser apenas espectador para fazer parte da vida urbana da comunidade de forma pontual. Deixar de ser o espaço invisível, em uma tentativa de valorizar seu interior, como um museu à céu aberto. Cuidado, preservado, lugar de apropriação coletiva das diversas manifestações culturais, seja nos rituais de sepultamento, seja nas obras de arte. Observa-se a partir dessas colocações que os cemitérios implicam na valorização do espaço funerário como "lugares de memória" (Pierre Nora, 1993).

A ideia do cemitério como fonte de pesquisa constitui grande parte da relevância da investigação aqui proposta e reside no fato de que a ação educativa com os alunos promove 
debate sobre o que discorrem a respeito da morte. Assim, convida a pensar historicamente a partir do meio. Lugares de memória podem ser entendidos como:

Os lugares de memória pertencem a dois domínios, que a tornam interessante, mas também complexa: simples e ambíguos naturais e artificiais, imediatamente oferecidos a mais sensível experiência e, ao mesmo tempo, sobressaindo da mais abstrata elaboração. São lugares, com efeito nos três sentidos da palavra, material, simbólico e funcional, simultaneamente, somente em graus diversos. (NORA, 1993:21)

A aula-visita ao cemitério proporciona redescobrir e incentivar o respeito ao outro como um ser que vive, mas que é frágil diante das conjecturas contemporâneas e das contradições sociais. Desta forma, teoricamente, esse reconhecimento da morte no espaço cemitério, pode suscitar sentimentos diversos, inclusive perceber a fragilidade da vida daqueles com quem convivemos e a nossa própria.

Nos cemitérios os símbolos são representação e comunicação de um sentimento, seja de perda ou aceitação. Toda produção artística presente nestes espaços pode conter mensagens que carecem de interpretação. Harry Rodrigues Bellomo, em "Os cemitérios do Rio Grande do Sul", apresenta as tipologias das esculturas funerárias, a beleza que traduz nos gestos, nas formas, nas expressões. Isto permite compreender os significados de algumas imagens que produziam sentimentos de consolação, aceitação, saudade, esperança, paz e fé. Existe uma intencionalidade nos símbolos, e além de representar o sentimento da perda, a ornamentação também declara a condição social do morto, pois quanto mais rica a família, mais suntuosos são os detalhes. Símbolos que compõem os acervos e sobrevivem ao tempo, desconhecidos, necessitando de conscientização dos órgãos públicos sobre a valorização e cuidado desse patrimônio cultural.

O cemitério possui características próprias. Enquadra-se na concepção de patrimônio, pois apresenta como lugar de expressão da morte e rituais presentes nas culturas dos povos, qualificadas como manifestação cultural material e imaterial. Conforme prevê a Constituição de 1988 quando define que:

Constitui patrimônio cultural brasileiro os bens de natureza material e imaterial, tomados individualmente ou em conjunto, portadores de referência à identidade, à ação, à memória dos diferentes grupos formadores da sociedade brasileira, nos quais se incluem: I - as formas de expressão; II - os modos de criar, fazer e viver; IIII - as criações científicas, artísticas e tecnológicas; IV - as obras, objetos, documentos, edificações e demais espaços destinados às manifestações artístico-culturais; V - os conjuntos urbanos e sítios de valor histórico, paisagístico, artístico, arqueológico, paleontológico, ecológico e científico. Constituição Federal Art. 216.

Desta forma, e expressão museu "a céu aberto" caracteriza o cemitério como sítios arqueológicos de valor histórico. O cemitério se relaciona com outros espaços em uma 
organização que permite o dialogo com a sociedade. A configuração de um tecido cultural costurado pelas memórias dentro do espaço cemitério permite visualizar condições favoráveis ao aprendizado. Refletindo sobre as condições indispensáveis para a educação, Brandão pondera:

A educação existe onde não há a escola e por toda parte pode haver redes e estruturas sociais de transferência de saber de uma geração a outra, onde ainda não foi sequer criada a sombra de algum modelo de ensino formal e centralizada. Porque a educação aprende com o homem a continuar o trabalho da vida. A vida que transporta de uma espécie para a outra, dentro da história da natureza, e de uma geração a outra de viventes, dentro da história da espécie, os princípios através dos quais a própria vida aprende e ensina a sobreviver e a evoluir em cada tipo de ser. (BRANDÃO, 1981:10)

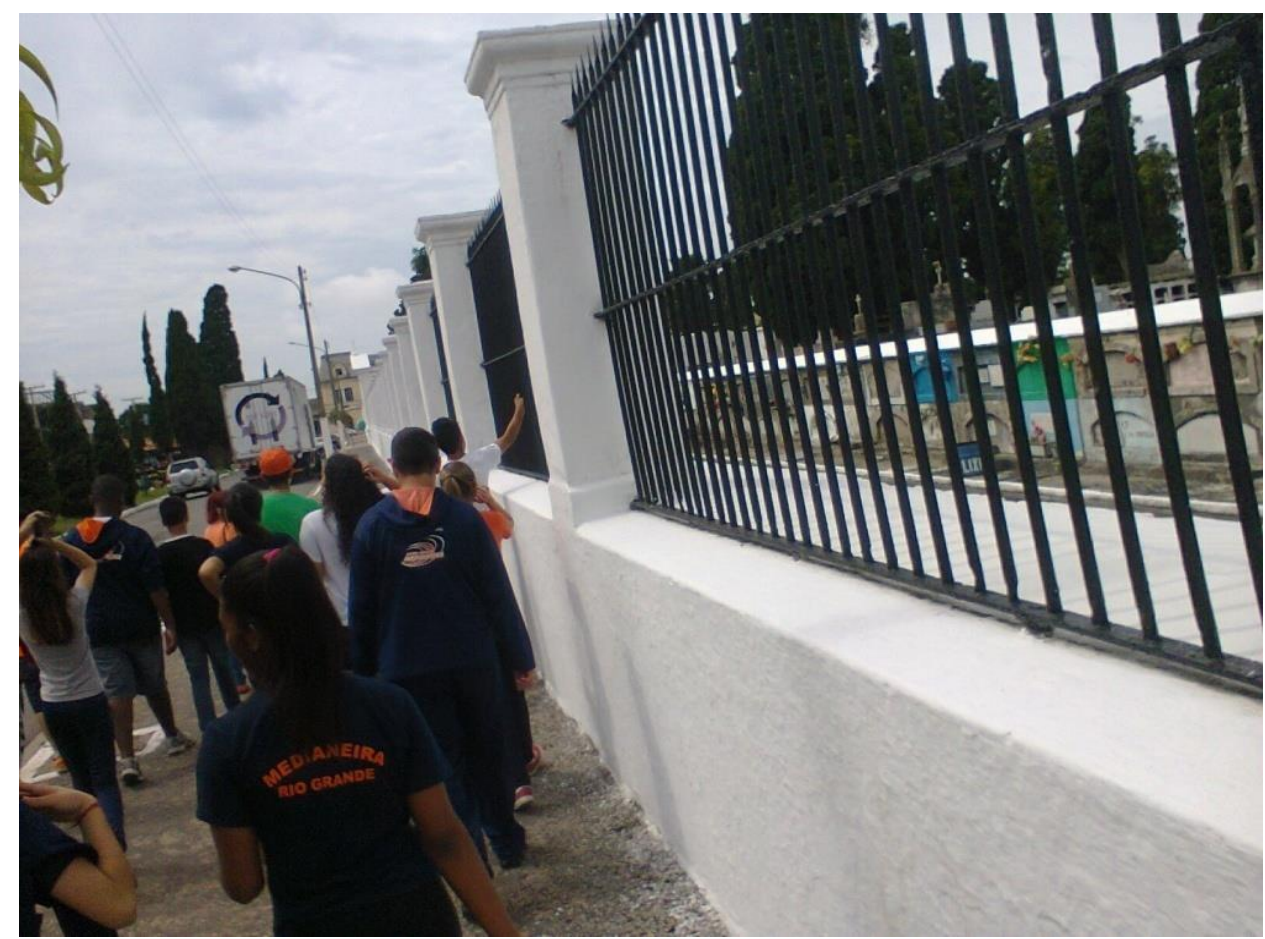

Fig.: 01 Alunos em visita ao cemitério católico do Rio Grande/RS

Fonte: Fotografia realizada pela autora.

A experiência pedagógica realizada nesse espaço (Fig.: 01) pertence ao universo dos temas geradores de interesse por estarem relacionados com a própria vida. Devido aos mistérios e aos tabus envolvendo os cemitérios, a configuração em que se apresentam, pode e pretende provocar interesse nos alunos em função do poder exercido sobre o imaginário adolescente e até mesmo nos adultos. Diante dessa atitude contemporânea de reconhecer o cemitério como lugar de ensino/aprendizagem informal, Brandão nos convida a pensar sobre a informalidade do aprender em lugares desprovidos de contingências educativas. Entretanto, repletos de significados e representações dos seres humanos. Ainda refletindo com Brandão sobre a educação, podemos pensar essa relação do cemitério com a vida e morte, aprender a viver, aprender a morrer. 
Ninguém escapa da educação. Em casa, na rua, na igreja ou na escola, de um modo ou de muitos todos nós envolvemos pedaços da vida com ela: para aprender, para ensinar, para aprender-e-ensinar. Para saber, para fazer, para ser ou para conviver, todos os dias misturamos a vida com a educação. (BRANDÃO, 1981: 07)

Nos cemitérios o ensino de História pode explorar o conteúdo curricular de forma a abranger aspectos educativos, por exemplo, estudando as imigrações a partir dos túmulos. Estudar os cemitérios é rever a transformação das cidades, pois a preocupação com os cuidados com os mortos, produziu verdadeiras obras de arte para ornamentar, decorar ou representar o sentimento de perda, resignação ou consolação, registrada pelas obras funerárias e na literatura. Pode-se pensar a relação dos sepultamentos, das esculturas e dos mausoléus com as classes sociais que se mostram historicamente excludentes. Fato que foi identificado pelos alunos assim que entraram no cemitério católico da cidade do Rio Grande/RS.

Em qualquer povoado, vila ou cidade encontram-se espaços destinados aos sepultamentos daqueles que amamos enquanto família, amigos, conhecidos e até mesmos desconhecidos. Lugares de pouca movimentação com exceção do dia dois de novembro no qual muitas pessoas vão homenagear seus entes queridos. Assim, em um movimento urbano, normalmente as pessoas transitam pelo exterior de suas paredes e não percebem a beleza ${ }^{2}$ do seu interior. O espaço é revelado como invisível, encontra-se na cidade, no entanto percebível apenas em sua característica funcional.

Pensar outras formas de conceber o cemitério é investir na possibilidade de espaço de ensino e cultura. Pensar o cemitério como museu a céu aberto ${ }^{3}$ é ponderar como fonte de pesquisa. Constitui um acervo histórico, cultural, social e político. De leituras e olhares inexplorados pelo ensino de História, pela Educação Patrimonial, pela Arqueologia, pelas Artes. Como desenvolver esse olhar sem a ótica mística e religiosa? Desconstruir esse processo respeitando as dimensões morais e religiosas parece nascer de uma necessidade de reconhecer esse espaço urbano como legitimo arquivo de memória, local de fonte documental e a permanente preocupação de preservação.

Nesse contexto o cemitério abrange aspectos específicos propícios para a educação e a formação do jovem estudante, pois articula os processos espaço/tempo na medida em que implica em reconhecer a morte como fenômeno natural e expõe ao mundo a fragilidade humana do inevitável.

O tentar compreender o espaço cemitério enquanto lugar de memória e História, abre perspectivas para refletir e analisar as relações educativas profícuas a partir da integração do 
jovem estudante com o meio. Surge assim a imensa rede de interligações com o lugar e a sua energia comunicativa, na qual o aluno desenvolve a capacidade de perguntar para aprender. Surge do interesse cognitivo e perceptivo, e não de uma imposição curricular. Conforme Carl Rogers (2010)

Quando um professor se preocupa mais em facilitar a aprendizagem do que exercer a função de ensinar, organiza o seu tempo e os seus esforços de modo diferente do convencional. Em vez de empregar a maior parte do tempo em preparar planos de aula e exposições orais, concentra-se na promoção de todas as espécies de recursos que poderão proporcionar a seus alunos uma aprendizagem experiencial correspondente às necessidades deles. (ROGERS, 2010:82)

Conhecimento de vida e morte inerente ao lugar, o cemitério, intitula-se nessa pesquisa como espaço de aprendizagem. Parte-se do pressuposto de que o cemitério, enquanto espaço de aprendizagem estão repletos de símbolos e significados, códigos estéticos e imagéticos. Códigos que comunicam sentimentos, religiosidade, fé, ou apenas abstração da morte. Porém, reconhece também algo que parece essencial à condição humana: o desejo da imortalidade.

O cemitério revela esteticamente o próprio inconsciente da sociedade através de uma trama simbólica, estruturada e organizada à volta de certos temas e mitos unificados por esta tarefa: reforçar, depois do caos, o cosmos dos vivos e imobilizar o devir, mesmo que se tenha de recorrer ao contraste (ambíguo) da imortalidade com o curso irreversível do tempo e da vida. (CATROGA,2010:170)

Assim, o cemitério cumpre uma função alternativa e relaciona o cotidiano de uma cidade com a morte. Pois como nasce alguém todos os dias, também morre alguém diariamente. Nessa dimensão paradoxal entre o viver e morrer, o ensino de história pode contribuir com a formação para a vida, pois revela o uso dos lugares e revela os domínios dos mistérios com a lógica e a ciência que lhe é peculiar. Não é possível continuar com um ensino de História preso as condições escolares e curriculares.

O cemitério ganha um novo sentido, não representa apenas um lugar para abrigar os mortos. Ao ser percorrido por adolescentes receosos e curiosos, resignifica o espaço mortuário, cria uma comunicação com a aprendizagem para a vida, constitui modos de transformar a relação do jovem com a morte, com o cemitério, com o conhecimento. Assim nas perguntas dos alunos um dos tópicos a ser levantado como possível indicação de plano de aula $^{4}$ foi a inauguração do cemitério de Rio Grande. O interesse girava em torno da data e motivos. Luiz Henrique Torres contribui com a produção da aula a partir da visita ao 
cemitério com as seguintes anotações:

Não podemos esquecer que neste um século e meio o cemitério extramuros foi um lugar de interação e continuidade com a vida cotidiana de muitas gerações que viveram nos espaços da casa e da rua da cidade do Rio Grande, gerações que estão ali sepultadas: portanto o cemitério transcende a sua condição de hospedagem dos mortos, para ser um lugar de intensa vibração de memórias, lembranças e emoções. (TORRES, 2006:133)

O processo de aprender história agencia descobertas e percorre caminhos inexplorados. Nesse processo, o viver e o morrer são questões cotidianas e podem estabelecer diálogos para compreender as limitações e analogias entre a vida e a morte. As experiências nos constituem, e a manutenção ou novos desafios dependem do quanto adquirimos de conhecimento da relação entre o viver e o morrer. Essa relação depende do que foi ofertado como conhecimento.

A professora de História, Doutora em Educação, Selva Guimarães Fonseca declara:

É possível afirmar que existe no Brasil uma diversidade de formas de ensinar e aprender história no decorrer do processo de implementação dos parâmetros curriculares Nacionais e dos sistemas nacionais e estaduais de avaliação de aprendizagem e de padronização dos critérios de avaliação dos livros didáticos. È interessante observar que se consolidou, entre nós, uma pluralidade de concepções teóricas, políticas, ideológicas e metodológicas no ensino de história. Esse fato requer algumas considerações, conforme já relacionado. (FONSECA 2009:36)

Em relação ao ensino de História, pode-se pensar em qual concepção de História foi ofertado. Verdades como absolutas, ou concepções da História como processo de transformação?

Desta forma as diferentes atitudes e atividades humanas durante o desenvolvimento do conhecimento e de transformações seculares são demonstradas na preocupação com as formas de cuidar e preservar seus mortos. Essa preocupação nos difere enquanto ser vivo. Conscientes do corpo que morre, as configurações sociais das diversas culturas permitem pensar que no ciclo da vida o evento morte se apresenta diversificado e com características reservadas para cada civilização.

Oportunizar a construção do conhecimento através da visita ao meio (Fig.: 02) (cemitério) como prática educacional que abarque os interesses dos alunos propicia-se condições para perceber o que o aluno quer aprender. Nessa perspectiva de "o que o aluno quer aprender", identificado pelas perguntas dos jovens estudantes ao percorrerem as ruas do cemitério Católico de Rio Grande-RS, foi revelado que o interesse do aluno concentra-se no meio cemitério (sua história) e na morte (seus percalços e mistérios). 


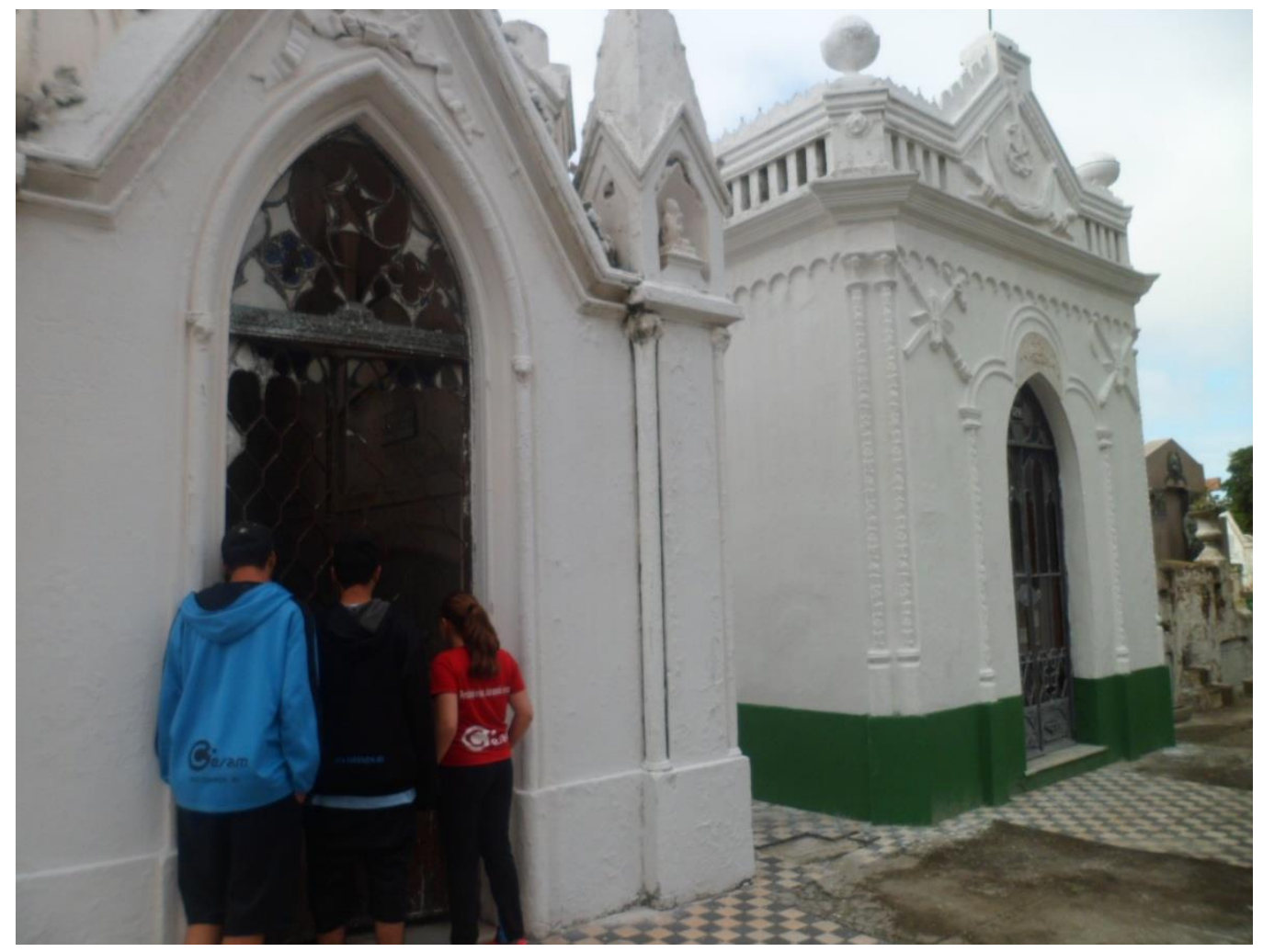

Fig.: 02 Alunos explorando o formato dos mausoléus Fonte: Fotografia realizada pela autora

Paulo Freire, do ponto de vista do fenômeno educativo vinculado aos espaços não formais ou na sala de aula como espaço considerado formal, incentivava o pensamento do educador de forma a compactuar com o meio, pois se aprende convivendo. Então, conforme Freire:

Ensinar não é transferir conhecimento, mas criar as possibilidades para a sua própria produção ou a sua construção. Quando entro em uma sala de aula devo estar sendo um ser aberto a indagações, à curiosidade, às perguntas dos alunos, as suas inibições; um ser crítico e inquiridor, inquieto em face da tarefa que tenho - a de ensinar e não a de transferir conhecimento. (FREIRE, 2002: 21).

Seria um equívoco supor que o meio sustenta o saber por si só. É necessário que aconteça o estímulo para preparar o campo de ensino, ou seja, a atitude do professor em perceber no conteúdo do livro didático ou em outro suporte, o momento para realizar atividades em ambientes externos. Depende de fatores como turma, do contexto curricular, da viabilidade em realizar a aula-visita, que podem se tornar fontes de provável averiguação e produção de um plano de aula com satisfatórios resultados para ambos Assim, parece necessário, um planejamento tático que avalie critérios curriculares da disciplina adaptados ao meio escolhido, envolvendo observação, sondagem e interesses dos alunos, entre outras ações importantes para efetivar a execução da experiência educativa. 
Ao longo do tempo em que se ensina História muitas foram as abordagens pedagógicas utilizadas para alcançar a atenção do aluno para os acontecimentos históricos e qual a relação com o presente. Entre rupturas e continuidades, ao praticar o ato de ensinar, o professor também aprende a refletir e revisitar suas práticas, e a partir delas perceber a efetiva ação do ensinar sobre os alunos. Não existe prática sem reflexão. Seria como proceder de forma mecanizada, sem se importar com os resultados. "Conseguiram atingir os objetivos da aula?" Diante de algumas frustrações, o professor de história procura recursos para realizar movimento, criar possibilidades.

Parte-se do pressuposto que a história é dinâmica e possui movimento. Antigas "verdades" desconstruídas por novas leituras, novas pesquisas, proporcionaram movimentos que inclui um passado incorporado ao presente, atribuindo significado. Mas qual o sentido desse passado para os nossos alunos? Nesse movimento, as possibilidades de estabelecer sentido entre o passado/presente muitas vezes se perdem nas deliberações dos órgãos competentes encarregados de determinar qual o conteúdo aplicado na disciplina.

$\mathrm{Na}$ escola acontece a troca de saberes entre professor e aluno, conhecimento docente e discente. Nesse espaço de ensino e aprendizagem advém a necessidade da comunicação entre esses sujeitos envolvidos no processo de ensinar/apreender.

Segundo Selva Guimarães Fonseca :

É na instituição escolar que as relações entre os saberes docentes e os saberes dos alunos defrontam-se com as demandas da sociedade em relação à reprodução, à transmissão e à produção de saberes e valores históricos e culturais. (FONSECA, 2009:130)

Com a imensa tarefa de "dar conta do conteúdo" os professores, muitas vezes esquecem de olhar a volta e perceber as possibilidades de ensino no ouvir. Ouvir os alunos, ouvir as perguntas que retornam da curiosidade e atentar aos saberes constituídos dos alunos. Pois, os mesmos possuem outras formas de adquirir conhecimento. Chegam na escola com conhecimentos adquiridos na família, nas relações sociais, no lazer, nas viagens. Nesse sentido, em todo lugar existe educação, apropriação de novos saberes.

Retoma-se as considerações de Brandão, “em todo o lugar ocorre educação”, a história está presente em tudo que rodeia o nosso dia a dia. Na comida, na roupa, no carro, no cinema, nas danças, nos cheiros, enfim, na vida e na morte. Fazer a mediação entre ensinar e aprender é percorrer espaços que incentivem a inovação da prática de ensino e o interesse do aluno. Nesse sentido procurar o espaço onde habita a memória coletiva e o acervo artístico apresenta-se como um ponto de partida para o desenvolvimento do eixo temático. Entre alguns desses espaços, elegeremos o cemitério como meio, no qual existem elementos 
invisíveis e, portanto, não associados diretamente pela memória social, porém, repletos de representações culturais. O local apresenta-se propício para o desenvolvimento da experiência educacional, onde o aluno entra em contato com elementos que compõe o patrimônio cultural e social da comunidade. O cemitério possui um caráter fortemente ligado ao imaginário e apresenta-se como um ambiente carregado de memória, embora haja poucos estudos e pesquisas no campo do ensino de História.

Pensando na prática pedagógica, e no estudo do meio, questiona-se como a aula/visita (representada pelo cemitério) pode gerar condições favoráveis para a construção do conhecimento. A produção de conhecimento teve como orientação a reflexão sobre a metodologia da saída de campo, a problemática do lugar e as narrativas dos alunos redirecionadas como perguntas, que por sua vez retornaram como aula expositiva dialogada e utilizaram vários recursos tecnológicos digitais.

A partir do local escolhido, o desafio foi criar possíveis metodologias que provoquem reflexões sobre a realidade próxima que o meio possibilita e dialogue com o processo formativo do aluno como cidadão consciente de seu papel na sociedade e no mundo. Através dessas atividades, e com objetivo de possibilitar ao adolescente a apropriação do conhecimento sobre as questões para a vida, um conjunto de mediações foi articulado e será apresentado nessa pesquisa.

\section{Da sala de aula à construção das etapas da experiência}

Toda ação pedagógica deve ser planejada, pensada, para contemplar os objetivos da aula. Todavia, na execução é que se percebe as contribuições do inesperado, do não esboçado. As palavras e atitudes espontâneas dos alunos diante das atividades propostas têm a força de provocar rupturas e reflexões sobre as teorias de aprendizagem e sobre o que se ensina. Pensando desta forma, as ações pedagógicas desta proposta compreendem um conjunto de atividades, compondo um mosaico de informações elaboradas de forma a promover a construção de um conhecimento que provoque nos adolescentes significados para a vida.

Alguns momentos foram pensados e se desenvolveram no decorrer das aulas, no andamento da exposição dialogada do conteúdo, pois mesmo com o planejamento da aula não se pode deixar de intuir outras possibilidades.

Para sistematizar o conhecimento, estrutura-se as etapas de forma a compreender as partes de um todo. Muitas das decisões na elaboração da ação educativa foram construídas a partir do movimento da sala de aula. As estratégias de ensino utilizadas antes e depois da aula/visita podem ser adaptadas às condições e maturidade da turma. Modificadas sempre que 
necessário. No entanto, o grau de autonomia nas decisões para essa prática deve seguir critérios. Critérios especificados pelos objetivos que se pretende.

O objetivo da aula não deve "se perder" diante da apatia ou do entusiasmo do aluno. De que objetivo? Refere-se ao ato de aprender a construir o conhecimento. Não seguir um rumo já trilhado, onde o educador pretende que o aluno "aprenda" um conteúdo préestabelecido e com os instrumentos e interpretações já determinados. Ao contrário, o objetivo é que o aluno seja partícipe da construção da aula, ou seja, são as considerações dos alunos sobre o conteúdo que possibilitem a introdução do Procedimento Invertido. Sendo assim, a finalidade principal é que o aluno realize suas próprias escolhas, exercite seu olhar sobre as fontes, crie suas próprias questões.

Claro está que isto implica em um encadeamento de etapas que são, a priori, estabelecidas pelo educador. Considerando que, cada etapa permita ao aluno a sua participação efetiva no processo, rompendo com a atitude passiva diante dos temas propostos.

Para a realização das etapas aqui sugerida, elegeu-se a Morte e o Cemitério como eixo temático. Pensa-se na presente relação destes elementos com os conteúdos curriculares do ensino de História e a construção da aula com um olhar diferenciado. Sendo assim, busca-se em todas as etapas contemplar os eixos temáticos conectados com o conteúdo curricular utilizando-se do livro didático, da poesia, da música, entre outros, que contribuam com a organização das aulas. Procura-se também desenvolver uma apreciação crítica da prática do ensino de História no ambiente cemitério, com vistas às adaptações que o procedimento requer para conseguir atingir os objetivos da aula e contemplar as ansiedades e curiosidades dos estudantes. O que pode ser apreendido nesse espaço? Qual a competência do cemitério e da morte para o ensino de História? Estaria esse espaço conectado com o que estávamos falando em sala de aula? Quais as perguntas que o lugar escolhido originará no estudante? As dúvidas na evolução das etapas se configuraram como prospecção para elaborar as aulas.

Os procedimentos metodológicos estão alicerçados nas experiências vividas no espaço da sala de aula, no cemitério e no envolvimento com a proposta, construindo um referencial. Assim ações educativas foram surgindo, compondo a proposta do Procedimento Invertido, com a intenção de verificar sua aplicabilidade ao ensino de História. Foram as perguntas que surgiram através do Procedimento Invertido que escoraram as possibilidades de aprendizagens tencionadas com a triangulação do eixo temático: Morte, cemitério e ensino de História. 


\section{MORTE e CEMITÉRIO}

- Valorizar e respeitar o outro.

- Conhecer os rituais funerários de várias sociedades.

- Reconhecer a diversidade cultural

- Religiões e religiosidade.

- Entre outros.

CONTEÚDO a ser explorado:

- Civilizações antigas

- Transformações da cidade

- Contexto social, político e econômico da sociedade

- Imigrações

- Identidade coletiva e individual

- Historicidade

- A História da Humanidade

- Entre outros

\section{Plano de aula "invertido"}




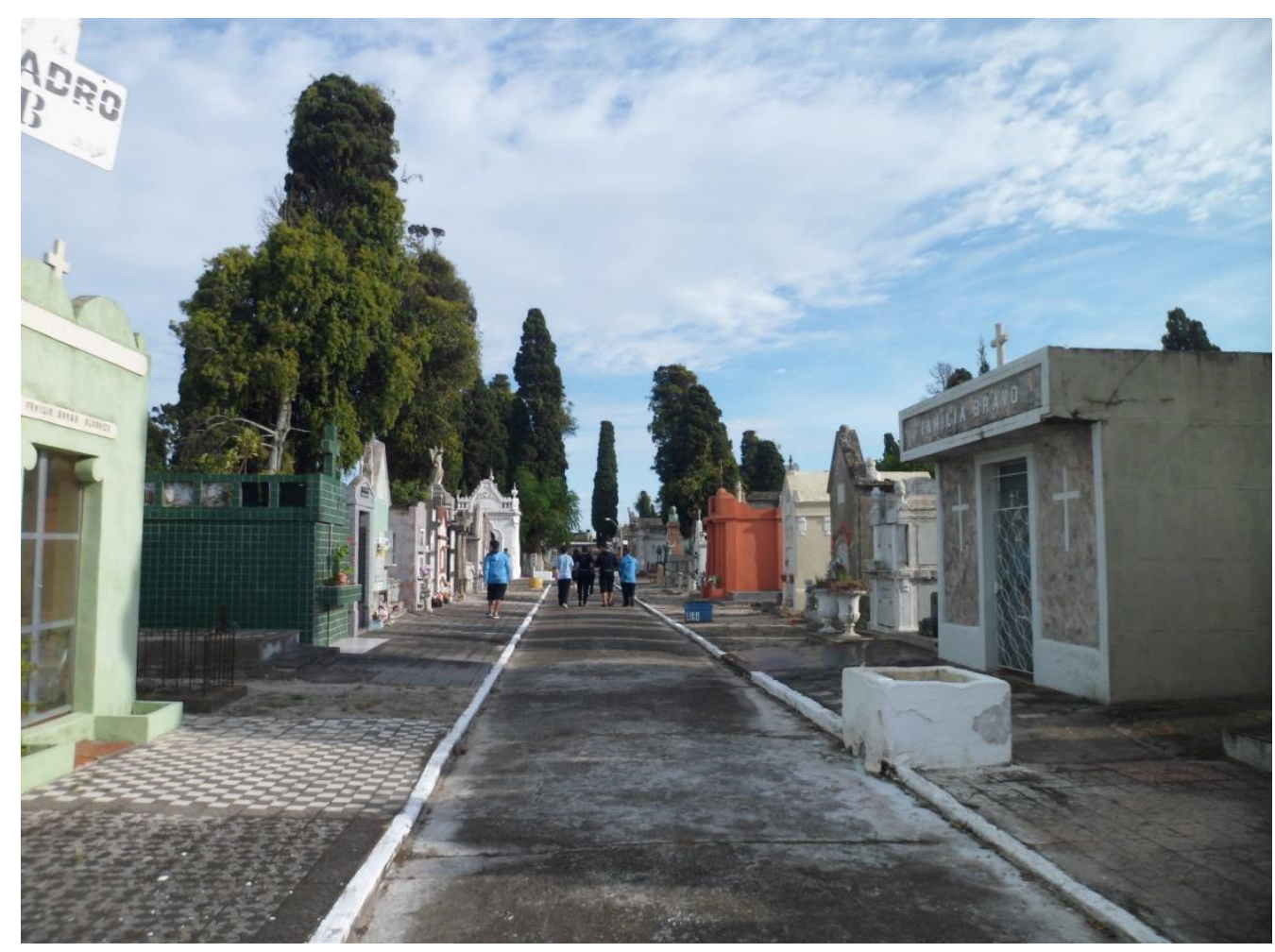

Fig.: 03. Aspectos panorâmicos de uma das ruas do Cemitério do Rio Grande/RS Fonte: Fotografia realizada pela autora

Os estímulos recebidos pelo meio aqui representados pelo espaço cemitério e pela temática da morte, conforme, a teoria de Piaget, aponta para a passagem de um estado de conhecimento mais elementar para um conhecimento elaborado. Piaget define que:

A criança, como o adulto, só executa alguma ação exterior ou mesmo inteiramente interior quando impulsionada por um motivo e este se traduz sempre sob a forma de uma necessidade (uma necessidade elementar ou um interesse, uma pergunta, etc.) (PIAGET, 1999: 15)

Nesse sentido, Piaget delibera sobre o desenvolvimento mental da criança e do adolescente, indicando que se trata de uma construção contínua, assegurando a passagem de qualquer estado de conhecimento para o nível seguinte pelos estímulos recebidos. Assim, o estudante conhece o espaço cemitério e recebe estímulos visuais. Mas o que esse espaço tem a dizer para a vida, para as questões humanas ou para o ensino de História? E como esse conhecimento pode ser considerado aprendizagem? O processo ensino e aprendizagem através da teoria piagetiana corroboram as hipóteses aqui levantadas. Assim como a teoria de Vygotsky estabelece a interação do meio como propicio para aprendizagem. São teóricos que divergem em alguns pontos em suas teorias, no entanto para o estudo aqui proposto, entendese que convergem nos sentidos apontados.

O espaço escolhido pelo contexto geográfico e histórico, tende a empreender um 
esforço do educador no que se refere a elaboração das etapas, pois se distancia de uma aula planejada nos moldes convencionais. Embora organizada e pensada, a aula procura estabelecer outros parâmetros de conduta. Pois a ação docente depende da interação professor/aluno e aluno/meio, dependente da liberdade e autonomia do aluno para que a aulavisita estimule a compreensão da proposta. Ou seja, observar, perguntar e compreender, considerando as potencialidades dos estudantes, seus pré-conhecimentos e suas intervenções, e que esse aprendizado seja significativo para a vida cotidiana. Sabe-se que diante da diversidade intelectual e educativa, alguns alunos conseguem realizar as relações aqui propostas, outros podem demorar mais um pouco.

\begin{tabular}{|c|c|}
\hline & Observação/atividades \\
\hline Inicio & Aula convencional, plano de aula, uso do livro, etc. \\
\hline \multirow[t]{3}{*}{01} & $\begin{array}{l}\text { Primeiro contato } \\
\text { Inserção da temática } \\
\text { Encontrar no conteúdo o momento apropriado para a inserção do tema, } \\
\text { Primeiro contato com a palavra morte e cemitério. } \\
\text { Solicitar as poesias ou música que contenham a temática e que dialoguem } \\
\text { com as palavras morte e cemitério }\end{array}$ \\
\hline & $\begin{array}{l}\text { Segundo contato } \\
\text { Leitura das poesias, letras de música. } \\
\text { Distribuição da Sondagem com as perguntas pré-elaboradas. }\end{array}$ \\
\hline & $\begin{array}{l}\text { Terceiro contato } \\
\text { Vídeo comedia sobre a morte e a elaboração das autorizações }\end{array}$ \\
\hline 02 & $\begin{array}{l}\text { Aula visita } \\
\text { Visita ao cemitério. } \\
\text { Solicitar que os alunos elaborem de } 02 \text { a } 03 \text { perguntas cada um. }\end{array}$ \\
\hline 03 & $\begin{array}{l}\text { Conversa sobre as perguntas e selecionar com o grupo quais os assuntos } \\
\text { serão conteúdos para a próxima aula } \\
\text { Relatos }\end{array}$ \\
\hline 04 & Organizar o plano de aula conforme as questões dos alunos \\
\hline $1^{\circ}$ aula & $\begin{array}{l}\text { Pergunta 01. Plano de aula } \\
\text { Pergunta 02. Plano de aula }\end{array}$ \\
\hline
\end{tabular}




\begin{tabular}{|l|l}
\hline $2^{\circ}$ aula & Pergunta 03. Plano de aula \\
& Pergunta 04. Plano de aula
\end{tabular}

Princípios que fundamentam as etapas do Procedimento Invertido:

1. Escolha do tema durante uma aula convencional.

Qual o conteúdo de História quer mediar?

Quais as estratégias e materiais podem ser usados?

O tema permite explorar a aula-visita de forma viável?

2. Escolha do meio
A intencionalidade.
O que queremos com essa experiência nesse espaço?
Quais os conceitos que podem surgir dessa aula-vista?
O lugar colabora por sua peculiaridade para elaboração de perguntas?

Suscita interesse e desperta a curiosidade?

3. Questionamentos dos alunos

Saber ouvir, solicitar ao aluno anotar duas ou três perguntas.

Interesse surge dos alunos no local.

Elaborar o plano de aula a partir das perguntas selecionadas

4. Plano de aula

Assuntos relacionados ao conteúdo curricular geral desdobrado em pequenos blocos de aula a partir das perguntas dos alunos.

A forma de realizar o plano de aula "invertido" possibilita ao aluno construir o conhecimento sobre a história a partir do espaço cemitério e da morte, com os estímulos visuais que permeiam o espaço da aula-visita. Nesse sentido, as perguntas que formam o plano de aula vêm ao encontro do que Rogers (2010) compartilha:

Assim, e agora. De modo que agora, com certo alívio, volto-me para uma atividade, um propósito, que realmente me apaixona - a facilitação da aprendizagem. Quando sou capaz de transformar um grupo - e com isso quero significar todos os membros do grupo, inclusive eu - numa comunidade de aprendizes ou estudantes, a emoção se torna quase inacreditável. Liberar a curiosidade; permitir que indivíduos arremetam em novas direções ditadas pelos seus próprios interesses; tirar o freio do 
sentido de indagação; abrir tudo ao questionamento e à exploração; reconhecer que tudo se acha em processo de mudança - eis uma experiência que jamais posso esquecer. Nem sempre posso alcançá-la nos grupos com que me associo, mas, quando ela é em parte, pequena ou grande, alcançada, torna-se então uma experiência grupal a não ser nunca esquecida. (ROGERS, 2010:42)

Com a elaboração das perguntas pelos alunos, a aula segue em direção à uma aprendizagem significativa devido o envolvimento dos estudantes com todo o processo. Percebe-se o resultado da ação educativa (reflexão sobre a prática) através dos depoimentos em forma de relatos, no qual o aluno se percebe como produtor da sua história e participante do processo de aprender. Desta forma, o pertencimento e a valorização do meio, da história social, história cultural ou outro tema, desde que sejam evidenciados durante o processo, contribuem com a aprendizagem significativa. Da mesma forma a abordagem metodológica utilizada visa a ampliação dessa ideia de que somente faz sentido aquilo que permeia o cotidiano do aluno ou o meio estudado.

\section{Referências}

ABUD, Kátia Maria; SILVA, André Chaves de Melo; ALVES, Ronaldo Cardoso. Ensino de História. São Paulo: Editora Cengage Learning, 2013 (Coleção Ideias em Ação coordenadora: Ana Maria Pessoa de Carvalho).

ARIÈS, Philippe. História da morte no Ocidente: Da Idade Média aos Nossos Dias. Rio de Janeiro: Ediouro. 2003.

ARROYO, Miguel. Currículo, território em disputa Petrópolis, RJ: Vozes, 2011

Miguel. Indagações sobre currículo: educandos e educadores: seus direitos e o currículo. Brasília: Ministério da Educação, Secretaria de Educação Básica, 2007

BELLOMO, Harry (org.). Cemitérios do Rio Grande do Sul: arte, sociedade, ideologia. Porto Alegre: EDIPUCRS, 2008.

BITTENCOURT, Circe Maria. O saber histórico na sala de aula. Circe Bittencourt (org.) 12 ed. São Paulo: Contexto, 2013.

2011.

, Circe Maria. Ensino de história: fundamentos e métodos. - 4. ed. - São Paulo: Cortez,

BORGES, Maria Elizia. Imagens da morte: monumentos funerários e análise dos historiadores da arte. Anais do XXVI Simpósio Nacional de História - ANPUH • São Paulo, julho 2011 Acesso em Nov/2015.

Maria Elizia; DOS SANTOS, Alcineia Rodrigues; GOMES, Larissa. Estudos Cemiteriais no Brasil: catálogo de livros, teses, dissertações e artigos. Goiânia: 
UFG/FAW/Ciar/FUNAPE, 2010.

, Maria Elizia. Arte funerária no Brasil. (1890-1930) oficio dos marmoristas italianos em Ribeirão Preto. Belo Horizonte: Editora C/ Arte, 2002.

BRANDÃO, Carlos R. O que é educação. São Paulo: Brasiliense, 1981

BRASIL (Ministério da Educação). Parâmetros curriculares nacionais: História. Brasília: ME, 1998

BRASIL, Secretaria de Educação Fundamental. Parâmetros Curriculares. Pluralidade cultural, http://portal.mec.gov.br/seb/arquivos/pdf/pluralidade.pdf Acessado em 10.10. 2015.

BURKE, Peter. O que é história cultural. Rio de Janeiro: Jorge Zahar, 2005.

CANETTI, Elias e ADORNO, Theodor W, Diálogo sobre massas, o medo e a morte, in Novos Estudos CEBRAP \# 21, JUL.1998, PP.116-132.

CATROGA, Fernando. $O$ culto dos mortos como uma poética da ausência ArtCultura : Revista de História, Cultura e Arte, v. 12, n. 20, jan.-jun. 2010. — Uberlândia: Universidade Federal de Uberlândia, Instituto de História http://www.artcultura.inhis.ufu.br/anteriorNr20.php acesso em 15.11.2015.

CERRI, Luis Fernando. Os conceitos de consciência histórica e os desafios da didática da História Revista de História Regional 6(2): 93-112, Inverno 2001 . Acesso em Jan/2016

CHEVALLARD, Yves. La transposición didáctica: del saber sabio al saber enseñado. Buenos Aires: Aique Grupo Editor, 2005.

CHERVEL, André. História das disciplinas escolares: reflexões sobre um campo de pesquisa in Teoria \& Educação. N. 2. Porto Alegre: Pannonica, 1990.

DOBERSTEIN, Arnoldo Walter. Estatuários, catolicismo e gauchismo, EDIPUCRS, 2002, $372 \mathrm{p}$.

ELIAS, Norbert A solidão dos moribundos, seguido de Envelhecer e morrer. 1897-1990 / Norbert Elias; tradução, Plínio Dentzien. - Rio de Janeiro: Zahar, 2001.

FONSECA, Selva Guimarães. Didática e prática de ensino de história. São Paulo: Papirus, 8 a edição, 2009.

FOUCAULT, Michel. Outros Espaços. In: (Org.:). MOTTA, Manoel Barros Michel Foucault. Estética: Literatura e Pintura, Música e Cinema. Rio de Janeiro: Forense Universitária, 2001.

FUNARI, Pedro Paulo. Desaparecimento e emergência dos grupos subordinados na arqueologia brasileira. Horizontes Antropológicos, Porto Alegre, ano 8, n. 18, p. 131-153, dezembro de 2002. http://www.scielo.br/pdf/ha/v8n18/19059.pdf Acesso em Jan/2016.

FUSARI, José Cerchi. O Planejamento do Trabalho Pedagógico: Algumas Indagações e Tentativas de Respostas. 1990 http://www.crmariocovas.sp.gov.br/pdf/ideias_08_p044- 
KOVÁCS, Maria Julia. Educação para a morte. Temas e reflexões. São Paulo: Casa do Psicólogo: Fapesp, 2003.

KARNAL, Leandro. História na sala de aula: conceitos, práticas e propostas. São Paulo: Contexto, 2003.

LUCKESI, Carlos C. Filosofia da educação. São Paulo: Cortez Editora, 2005.

LUTZ, Berta Maria Julia. A função educativa dos museus. Rio de Janeiro: Faperj, 2008.

MARANHÃO, José Luiz de Souza. O que é morte. São Paulo: Brasiliense, 1998

MENEZES, Ebenezer Takuno de; SANTOS, Thais Helena dos. "Transversalidade" (verbete).

MORIN, Edgar. A cabeça bem-feita: repensar a reforma, reformar o pensamento. Tradução de Eloá Jacobina. 9. ed. Rio de Janeiro: Bertrand Brasil, 2004.

O homem e a morte. Lisboa: Europa - América, 1997

NORA, Pierre. Entre memória e história: a problemática dos lugares, In: Projeto História: PUC, n. 10, p. 07-28, 1993.

OTOBELLI, Danúbia. Benedictus: os cemitérios de Flores da Cunha: arte, história e ideologia / Danúbia Otobelli, Gissely Lavatto Vailatti - Flores da Cunha: Seculum, 2007.

PASTORE, Maria Cristina. A cidade dos mortos a cidade dos vivos: diálogos possíveis entre a escultura funerária e o cotidiano escolar. Trabalho de conclusão de curso (graduação) Universidade Federal do Rio Grande - FURG, Instituto de Letras e Artes - ILA, Artes visuais Licenciatura. 2013 disponível biblioteca virtual FURG

Cemitério: Um lugar (in) explorado pelo ensino de arte. Disponível em: https://docs.google.com/file/d/0B9hrI7rJtjwqM0d2OXFKMlE0a0U/edit Acessado em 10.10.2015

Procedimento invertido: O Ensino de História a partir das inquietações de jovens estudantes sobre a morte na aula-visita ao cemitério. Dissertação (Mestrado em História, Pesquisa e Vivências de Ensino-Aprendizagem) - Universidade Federal do Rio Grande, Rio Grande: 2016. Disponível biblioteca virtual FURG

PAZ, Octavio. El laberinto de la soledad Primera edición (Cuadernos Americanos), 1950

PERRENOUD, Philippe. Dez novas competências para ensinar: convite à viagem. Porto Alegre: Artmed, 2000.

PINSKY, Carla Bassanezi. Novos temas nas aulas de história. São Paulo- Contexto, 2009.

PINSKY, Jaime. O ensino de História e a criação do fato. Jaime Pinsky (autor e organizador) - 14. Ed. - São Paulo: contexto, 2011.

REIS, João José, 1952- A morte é uma festa: ritos fúnebres e revolta popular no Brasil do 
século XIX / João José Reis. - São Paulo: Companhia das Letras, 1991.

RIGO, Kate. Pedagogia Cemiterial: Uma Possibilidade de Ação nas Aulas de Ensino Religioso

https://www.academia.edu/7621187/Pedagogia_Cemiterial_Uma_Possibilidade_de_A\%C3\% A7\%C3\%A3o_nas_Aulas_de_Ensino_Religioso Acesso em Jul/2016

ROGERS, Carl R. Liberdade de aprender. Tradução de Edgar Godoi da Mata Machado e Márcio Paulo de Andrade, Prefácio do Prof. Ruy Miranda. 4 ed. Belo Horizonte. Interlivros. 1977.

Carl, R. Zimring, Fred. Carl Rogers / Fred Zimring; tradução e organização: Marco Antônio Lorieri. - Recife: Fundação Joaquim Nabuco, Editora Massangana, 2010. http://livros01.livrosgratis.com.br/me4665.pdf Acesso em Abril/2016.

SCHMIDT, Maria Auxiliadora. A formação do professor de História e o cotidiano da sala de aula. In: BITTENCOURT, Circe Maria Fernandes. O saber histórico na sala de aula.12.ed. São Paulo: Contexto, 2013

SCHIMIDT, Maria Auxiliadora \& CAINELLI, Marlene. Ensinar História. 2 ed. São Paulo:Scipione, 2009, pp. 111-136

TORRES, Luiz Henrique. Rio Grande em tempo de cólera Rio Grande: Pluscom Editora, 2015

, A morte é o centro das atenções: o regimento do cemitério extramuros (1859),2006. disponível em: https://www.seer.furg.br/biblos/article/view/259 2006 Acesso em jul/2015.

VELASCO, Diego Bruno. "Realidade do Aluno", "Cidadão Crítico", "Conhecimento Escolar”: Que articulações possíveis no Currículo de História? II. Rio de Janeiro, 2013. Dissertação (Mestrado em Educação) - Faculdade de Educação, Universidade Federal do Rio de Janeiro, Rio de Janeiro, 2013. 